\title{
Stereotactic tractotomy in the surgical treatment of mental illness
}

\author{
GEOFFREY KNIGHT \\ From the Department of Surgery, Postgraduate Medical School of London
}

It must be accepted that the principle of surgical treatment in mental illness is regarded with disfavour by certain psychiatrists, for the disappointing results produced by the extensive destruction of the frontal white matter in the old standard leucotomy are not readily forgotten. Of the large number of operations which were performed in the early years two-thirds were upon schizophrenics, a group which yield the least satisfactory results, fewer than one fifth making a good recovery and only one third being ultimately discharged from hospital. Patients in whom the operation failed therefore tended to accumulate in mental hospitals and they form an increasing source of discouragement to psychiatrists (Pippard, 1962). Against this background the good results claimed for modern selective operations in the treatment of psychoneurosis are sometimes regarded with scepticism. The introduction of new forms of drug treatment led to the suggestions that within a few years the need for surgical treatment would be eliminated, yet, although drug treatment has been very successful, there are still a number of patients both in psychiatric out-patient departments and in mental hospitals who continue to be crippled with chronic or recurrent symptoms despite the use of all available methods other than surgery. Therefore there is still a substantial demand for the so-called psycho-surgical procedures in the treatment of some types of intractable psychosis. Our surgical proce- dure has, however, changed in recent years owing to $\frac{\bar{\partial}}{\bar{N}}$ the addition of a new method of stereotactic opera- $\frac{D}{\sigma}$ tion to the already existing methods of treatment. $\stackrel{\mathbb{2}}{\complement}$ Thus between the years 1950 and 1965 we carried out $\%$ over 550 restricted orbital undercutting operations $\rightarrow$ (Knight and Tredgold, 1955). This consists of $\odot$ forming an incision in each frontal lobe extending $\vec{\omega}$ backwards for a distance of $6 \mathrm{~cm}$. from each frontal pole in the subcortical white matter immediately above the orbital cortex; each incision is $1.8 \mathrm{~cm}$. wide and lies $1 \mathrm{~cm}$. above the level of the orbital $\infty$ roof, the medial margin of the cut extending to within $1 \mathrm{~cm}$. of the middle line (see Fig. 1B). TRe terminal $2 \mathrm{~cm}$. of the incision enters the substant innominata beneath the head of the caudate nucle and here overlies the agranular cortex of area which commences at a point $4 \mathrm{~cm}$. from the frontal pole and extends posteriorly to a distance of $6.3 \mathrm{ch} \cdot \frac{\mathrm{C}}{\mathrm{c}}$ from the tip of the pole (Beck, 1949) (Fig. 1A. Although the results of this operation were usuag good (Table I) some of our experiences indicated that it was the posterior part of this incision in the substantia innominata (Fig. 2) which was specially? concerned with the best therapeutic effects (Knight, $\frac{\partial}{0}$ 1960), and for this reason we developed in 1961 a stereotactic method directed towards making some small destructive lesions solely in this area. It appeared probable that such a procedure would pro- $\frac{0}{3}$ vide a good clinical result, at the same time reducing
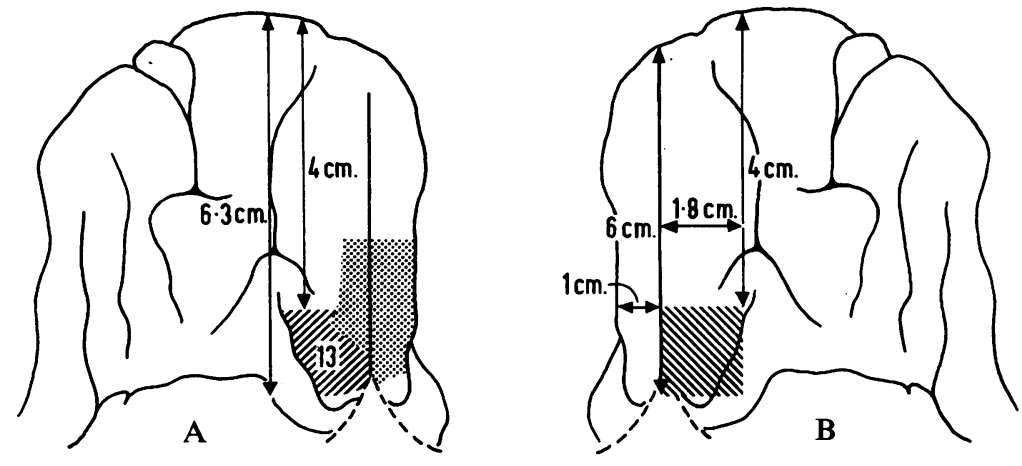

304
FIG. 1. A Orbital aspect of right frontal lobe, showing area 13 in cross hatch and area 14 in stipple.

$B$ Orbital aspect of lef르. frontal lobe, showing site of incision employed, $1.8 \mathrm{~cm} \cdot \frac{3}{3}$ wide, situated $1 \mathrm{~cm}$. from mid-0 line, extending to $6 \mathrm{~cm}$. from the frontal pole. The last $2 \mathrm{~cm} D$ corresponds to area 13 (see A). 
the hazards of cutting, particularly in elderly patients, and by reducing brain scarring lower the risk of epilepsy and undesirable personality change.

Anatomically the substantia innominata contains few afferent fibres from the ascending thalamofrontal radiation, and indeed lies well below and largely behind it (Fig. 2). In coronal section the ascending thalamo-frontal radiation is in relation to the lateral and anterior aspect of the substantia whereas the genu of the corpus callosum is on its medial and posterior aspects (Fig. 3). This region contains fibre tracts passing from and to distant cortical areas and to the hypothalamus. (Le Gros Clark and Meyer, 1950; Wall, Glees, and Fulton,
1951; Cowan and Powell, 1956; Nauta, 1961; Powell, Cowan, and Raisman, 1963, and it may be that a tractotomy confined to certain of these pathways is significant in producing the effects observed. Vertical incisions in this area, however, produce serious autonomic and trophic disturbances (Knight, 1943; Meyer and Beck, 1954; Ziegler and Osgood, 1945; Beck, McLardy, and Meyer, 1950), which are attributable to associated damage to the striatum (Meyer and McLardy, 1948) indicating that the substantia should not be approached from above and that in a stereotactic operation a strictly localized lesion should be formed in the substantia innominata by a destructive agent which could not produce

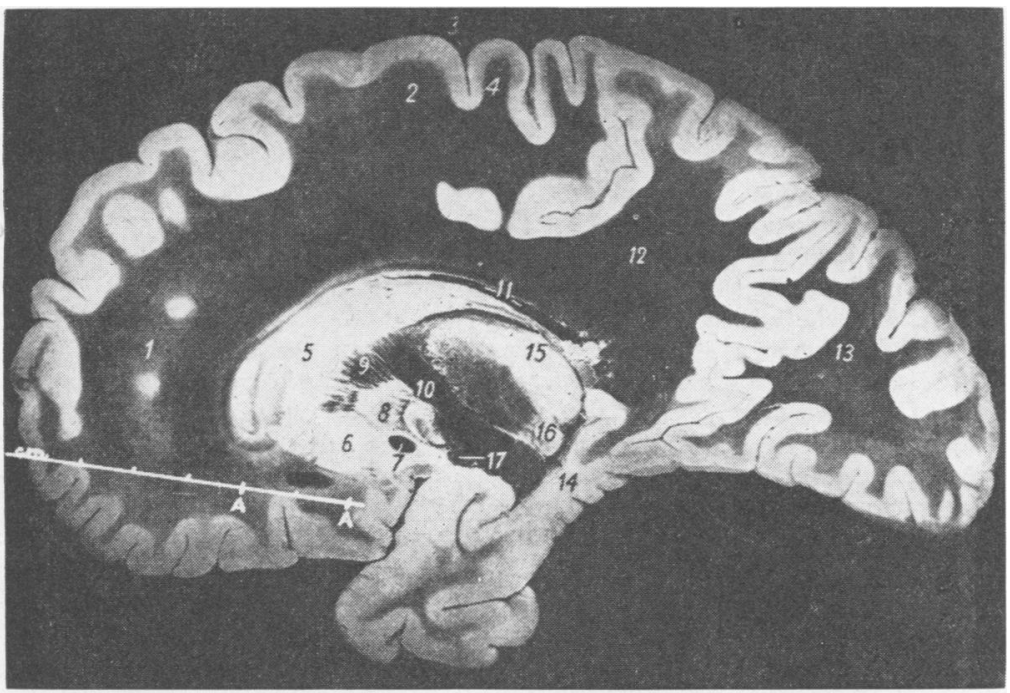

FIG. 2. Sagittal section of left frontal lobe showing the situation of the $6 \mathrm{~cm}$. incision and $A-A$ the last $2 \mathrm{~cm}$. of that incision in the substantia innominata. The underlying cortical area 13 lies behind and below the ascending thalamo-frontal radiation, which passes between the caudate nucleus (5) and putamen (6) (Figs. 2-3 reproduced by kind permission of Professor Stelmasiak and the Polish State Medical Publishers from 'The anatomical atlas of the human brain and spinal cord').

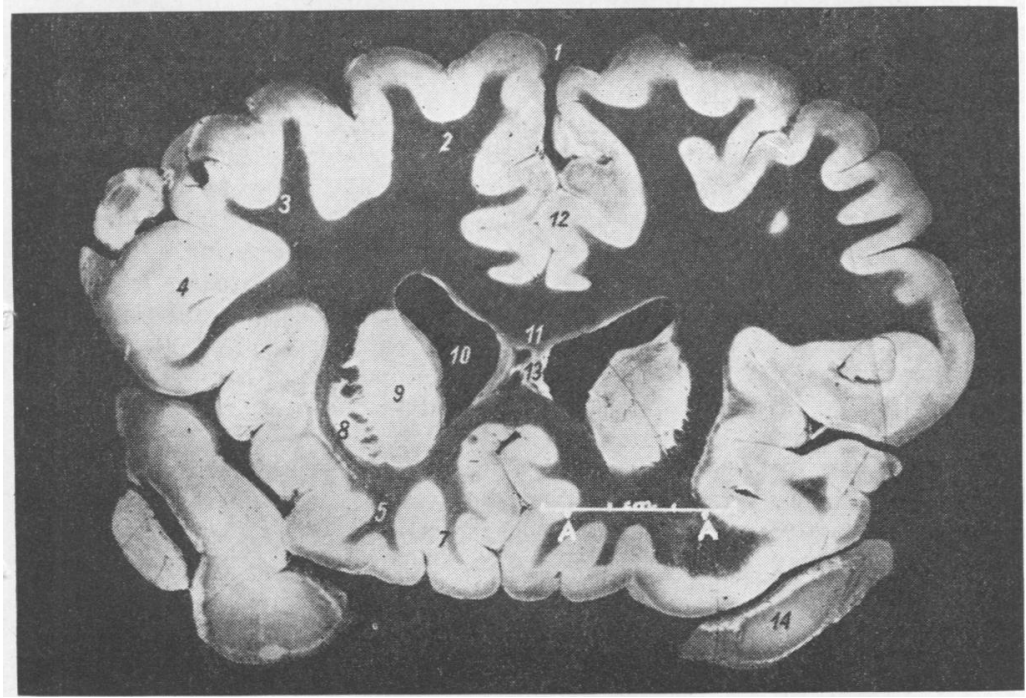

FIG. 3. Coronal section showing site of an incision approximately $1.8 \mathrm{~cm}$. wide in the substantia innominata. The thalamo-frontal radiation is in relation to its anterior and lateral aspect between the putamen (8) and the caudate nucleus (9). The genu of the corpus callosum descends from its inner aspect. 
marginal effects by infarction or haemorrhage in the region of the striatum. Although electrocoagulation or ultrasonic methods might prove to be satisfactory when the site and size of the optimum lesion had been finally determined, we decided for research purposes to use seeds of radioactive Ytrrium Y90 whose short range of emanation would ensure a strictly localized effect.

\section{STEREOTACTIC OPERATION}

In 1961 stereotactic operations were started in the Department of Surgery at Hammersmith Hospital with the cooperation of the Departments of Radiology and Physics. It was decided to form the equivalent of the terminal $2 \mathrm{~cm}$. of the undercutting incision and destroy a zone in the substantia innominata $2 \mathrm{~cm}$. long, $1.8 \mathrm{~cm}$. wide, lying at a height $1 \mathrm{~cm}$. above the orbital roof, the inner border of this plane extending to within $1 \mathrm{~cm}$. of the middle line and the posterior margin lying $0.5 \mathrm{~cm}$. in front of the plane of the tuberculum sellae, this latter site having been established by the insertion of opaque markers into the posterior end of the intracerebral incision at open operation. Two rows of four seeds of radioactive Ytrrium Y90 were implanted to irradiate the selected zone. The necrotic dose was empirically believed to be 30,000 rads. After initially using seeds of high dosage, $0.36 \mathrm{Mc}$., in the anterior row of seeds in the first 11 cases, it was decided to use seeds of uniform intensity, $0.15 \mathrm{Mc}$., throughout the plane. These seeds yield 38,000 rads at a distance of $1.5 \mathrm{~mm}$. from the seed's surface at the margin of the plane and from summation 41,000 to 45,000 rads at the same distance at certain points above and below the seeds. Since the seeds produce a necrotic dose of 38,000 rads up to $1.5 \mathrm{~mm}$. from their surfaces, they were implanted in such a pattern that the lateral margins of the outer rows lie at this distance inside the margin of the plane that it is proposed to destroy and the tips are at a similar distance from the anterior and posterior extremities of the plane (Figs. 6 and 7). Since the dosage outside the plane falls by $50 \%$ with each millimetre of distance, the lesion is nowhere thicker than $5 \mathrm{~mm}$.

In the earliest cases the implants were inserted on one side at a time at successive operations. It was interesting to observe only a minimal reduction of symptoms from a unilateral implantation, perhaps a modest reduction in the amount of sedation, followed by a marked improvement when the second side was completed, indicating how easily an open operation can miss its effect if the incision should deviate on one side and fail to reach the target over area 13. Bilateral implants have since been performed in one operation but the size of the lesion has been reduced. Certain observations indicated that it might be possible to confine the lesion to an area near the corpus callosum. After 30 cases we omitted the lateral row of seeds near the thalamo-frontal radiation and implanted the inner three rows only, the results being equally satisfactory. Recently, in two cases of severe recurrent depression a satisfactory and immediate response was obtained by using the inner two rows only. If this response

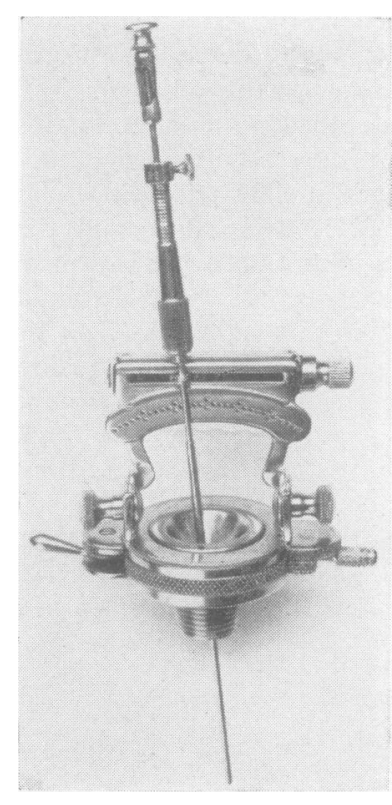

FIG. 4. McCaul'so stereotactic device with vernier scale and needle carrier attached to the perforated plate showing the implanting needle. with millimetre screw $\overrightarrow{=}$ adjustment to controt? depth of implantation set at $1 \mathrm{~cm}$. contro mark as for implanta- $\frac{\bar{s}}{\mathrm{~s}}$ tion of the anterior $\mathbb{\unrhd}$ row.

is maintained it may indicate the future possibility making a linear antero-posterior lesion in the inner patto of this area by electrical or ultrasonic methods, bout further time must elapse in order to judge the perma ence of the results.

A modification of McCaul's (1959) stereotactic devect was prepared by the addition of a needle carrier mounted ${ }^{\text {f }}$ on a moving vernier scale attached to the perforated plateo (Fig. 4). The implanting needle consisted of a hollow tutees with a lateral aperture for the introduction of the seeds and a removable stilette. The needle was fitted with ao movable collar containing a millimetre screw adjustment to control the depth of implantation of the deepest seed $; \overline{0}$ by undoing this collar the implanting needle could beo withdrawn to a centimetre mark and then fixed at this point by again screwing up the collar to ensure that the needle was withdrawn to this exact extent when the anterior row of seeds was implanted (Fig. 4). At operation the head is supported bilaterally in a polythene head rest with cassette holders at the side of, and beneath, the head? to contain the lateral and antero-posterior $x$-ray plates. To avoid any visible scar a suitable incision is planned according to the appearance of the brow, either in a skin:crease or creases or concealed in the hair margin after 3 . shaving a narrow zone of hair. After reflecting the scalpo and epicranium bifrontal burr holes are fashioned centred? $2 \mathrm{~cm}$. from the mid line as far down in the frontal plate as the position of the frontal sinuses will permit. After opening the dura and coagulating vessels which would be encountered by the implanting needle, the stereotactico device is screwed in, the aiming needle directed at the presumed target and corrected, first in the sagittal planeos (Fig. 5a) and then in the transverse plane (Fig. 5b) by $x$-ray control according to McCaul's technique.

The postero-medial angle of the plane to be im- $\omega$ 

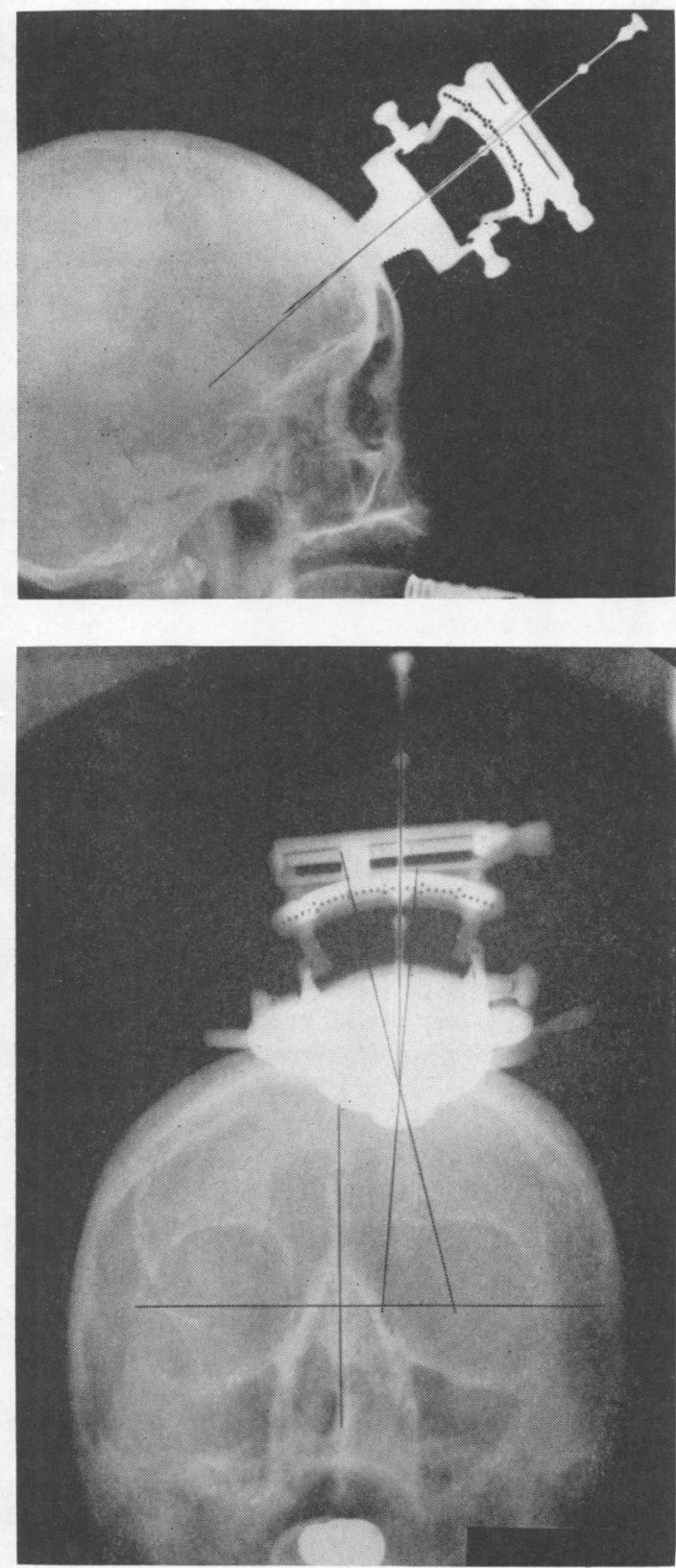

FIGs. 5a and 5b. Stereotactic device in situ in the sagittal (above) and the transverse (below) planes. The distances between the two spheres on the aiming needle corresponds to the distance between the lower sphere and the centre of rotation of the instrument. The site of the target area is marked on the radiograph, and a line projected from this point through the centre of rotation to cross the perforated scale. If the aiming needle is now moved to this point it will be directed accurately at the target in this plane. planted lies $0.5 \mathrm{~cm}$. in front of the plane of the tuberculum sellae, $1 \mathrm{~cm}$. above the orbital roof and $1 \mathrm{~cm}$. from the middle line. The radiological problem is that of placing the postero-medial seed in the correct situation to irradiate this site. With the stereotactic device in the sagittal plane a lateral film is taken centred on the pterion with a tube film distance of 48 in. which gives a $10 \%$ magnification factor. On this film a line is drawn from the tuberculum sellae along the orbital roof; a point is then marked off $5.5 \mathrm{~mm}$. in front of the tuberculum sellae to allow for magnification, a line is projected upwards at right angles to the base line at this point and on this line a point $11 \mathrm{~mm}$. above the base line indicates the posterior margin of the plane, the target point in this projection. The distance between the two spheres on the aiming needle corresponds to the distance between the lower sphere and the centre of rotation of the instrument. The site of the target area is marked on the radiograph, and a line projected from this point through the centre of rotation to cross the perforated scale. If the aiming needle is now moved to this point it will be directed accurately at the target in this plane. The stereotactic device is now rotated through 90 degrees into the transverse plane and a similar correction applied. Since the inner margin of the plane should lie $1 \mathrm{~cm}$. from the middle line and the seed itself should lie $1.5 \mathrm{~mm}$. inside the plane, a point $1.4 \mathrm{~cm}$. from the mid line is selected as a target area over the sphenoid wing and a line drawn from this target position through the centre of rotation of the instrument on to the scale (Fig. 5b). The aiming needle is corrected to this point and is now on target for the inner line of seeds. The depth. of the needle point for sowing the deepest seed is now determined. The distance from the target point to the rim of the stereotactic device within the skull is measured on the radiograph. From this distance is deducted the length of the seed, $7 \mathrm{~mm}$., and the distance that the seed should lie within the plane, $1.5 \mathrm{~mm}$., plus an overall $10 \%$ magnification factor which will give the true distance that the tip of the needle should project beyond the rim of the instrument in order to implant the deepest seed. By subtracting this figure from the known maximum depth of the needle the amount of correction required on the millimetre screw adjustment can be determined. The correction is applied, the implanting needle is inserted, and the position checked radiologically.

The deepest seed is inserted, the needle withdrawn to the centimetre mark and the anterior seed is inserted; the needle is withdrawn and the vernier moved to the next site of implantation and the process repeated until the necessary number of lines are sown at regular intervals (Figs. 6 and 7). A similar procedure is then employed on the opposite side. After operation the burr holes are filled with plastic buttons and covered with epicranium to give a good cosmetic result. In patients whose wrinkles do not completely traverse the brow a satisfactory effect may be obtained by an incision which crosses from one wrinkle to another; if the skin is returned accurately to its original position such a scar may be hard to identify.

\section{POST-OPERATIVE COURSE}

In the first 11 cases in which 'hot' seeds were 


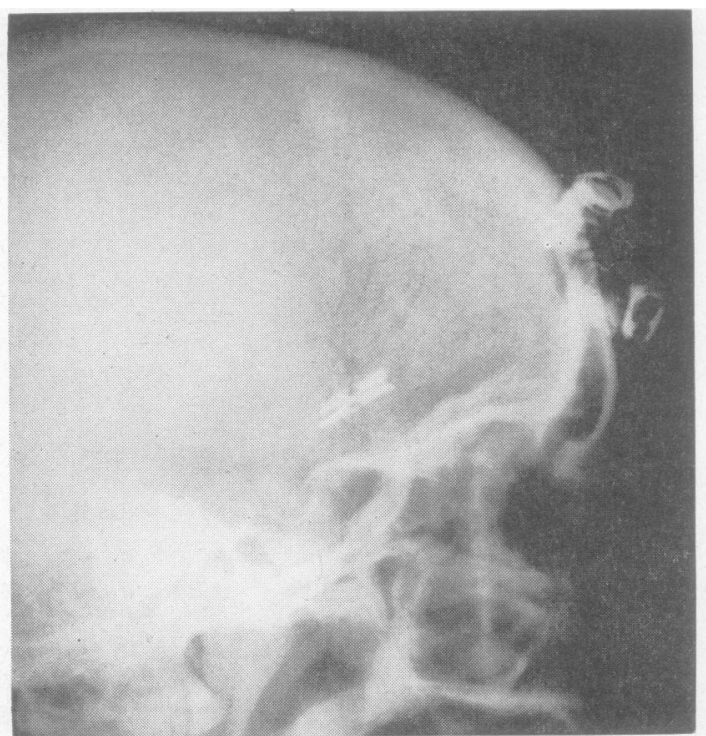

FIG. 6. Lateral radiograph showing bilateral implants in situ.

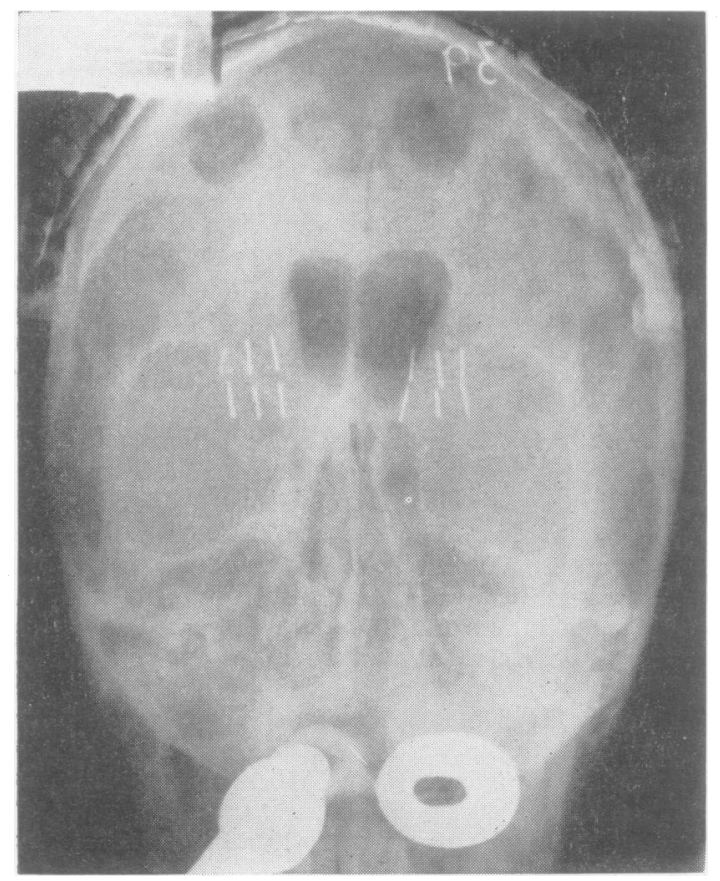

Fig. 7. Antero-posterior radiograph with $30^{\circ}$ tube tilt showing bilateral implants of three lines in a patient who had previously had an air encephalograph performed. In two recent cases only the inner two rows have been implanted. employed in the anterior row, a temporary phase of $Z$

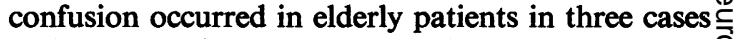
and lethargy in four cases during the early postoperative weeks, but subsequently resolved. In the remainder treated with seeds of lower intensity, 0 confusion was seen for a time in two elderly subjects, and a temporary lethargy occurred in three elderly $\frac{\rho}{\square}$ patients. In general the post-operative course is $\underset{\overrightarrow{0}}{\overrightarrow{2}}$ very satisfactory with little trace of any traumatic. syndrome. There is no evidence of any undesirable $\vec{F}$ personality change.

\section{RESULTS}

The degree of recovery depends upon many factors; $\frac{\overline{\bar{p}}}{\overrightarrow{\mathrm{D}}}$ the nature of the psychiatric illness, the personality 2 of the individual, the environment to which he must $\%$ return, and the degree of psychiatric and home $\vec{O}$ support provided in the early stages. The last factor is extremely important.

It is not intended to attempt to present a detailed survey of the patients operated upon but merely to present certain clinical gradings from the post-? operative assessment of the referring psychiatrists in $\infty$ 450 cases for which the restricted undercutting operation was used and in 50 cases in which the stereotactic operation was used.

A clinical assessment of the results of the orbit undercutting operation has already been published (Sykes and Tredgold, 1964; Knight, 1964), and thee results are again summarized in Table I. In Table $\frac{\text { f }}{\mathrm{C}}$ the results of the stereotactic procedure are presented in a similar pattern. The age distribution of the patients is given in Table III and from this it will be $\overrightarrow{\mathrm{b}}$ seen that there is a substantial shift to the later age groups as far as the second operation is concerned.

All the patients treated in both series had pre- $\frac{\bar{O}}{0}$ viously received psychiatric treatment for many years. Since the results of stereotactic operation have $\stackrel{\odot}{\mathcal{D}}$ been consistant and well maintained, certain refer- $\Rightarrow$ ring psychiatrists now tend to refer cases of resistant $\frac{0}{3}$ depression for operation within two years when they fail to relieve symptoms by medical means.

The results obtained in the first 50 cases of stereotactic operation (see Table II) show a marked improvement in cases of depression. Satisfactory results were obtained in some patients with obsessional illness and anxiety states and in certain hysterics and hypochondriacs but the number of cases is insufficient to draw any comparison with the results obtained by undercutting. Stereotactic implantation $\frac{\mathrm{O}}{3}$ is useless in the treatment of chronic pain. Two $\frac{D}{O}$ previous failed leucotomies were improved.

Relapse after initial improvement is uncommon.

$$
\text { DISCUSSION }
$$

The atraumatic nature of the stereotactic operation 
TABLE I

POST-OPERATIVE RESULTS ANALYSED IN RELATION TO TYPE OF PSYCHIATRIC ILLNESS IN 450 CASES OF RESTRICTED ORBITAL UNDERCUTTING

\begin{tabular}{|c|c|c|c|c|c|}
\hline \multirow[b]{2}{*}{ Diagnosis } & \multicolumn{2}{|c|}{ Free from Medical Care } & \multirow[b]{2}{*}{$\begin{array}{l}\text { Grade 3: Improved, } \\
\text { Some Symptoms } \\
\text { Requiring Treatment }\end{array}$} & \multirow[b]{2}{*}{ Grade 4: Unchanged } & \multirow[b]{2}{*}{ Grade 5: Deteriorated } \\
\hline & $\begin{array}{l}\text { Grade 1: No } \\
\text { Symptoms }\end{array}$ & $\begin{array}{l}\text { Grade 2: Slight } \\
\text { Symptoms and No } \\
\text { Treatment Required }\end{array}$ & & & \\
\hline $\begin{array}{l}\text { Schizophrenia } \\
\text { Hypochondriasis, chronic pain, } \\
\text { mixed syndrome, including }\end{array}$ & 5 & 11 & 25 & 25 & - \\
\hline psychopathy & - & 5 & 9 & 12 & - \\
\hline Hysteria & 1 & 2 & 4 & 6 & 1 \\
\hline Obsessional compulsive states & 13 & 15 & 24 & 12 & 1 \\
\hline Anxiety states & 8 & 26 & 20 & 4 & - \\
\hline Depressions & 91 & 64 & 52 & 11 & 3 \\
\hline Total & 118 & 123 & 134 & 70 & 5 \\
\hline
\end{tabular}

TABLE II

POST-OPERATIVE RESULTS ANALYSED IN RELATION TO TYPE OF PSYCHIATRIC ILLNESS IN 50 CASES OF STEREOTACTIC OPERATION

\begin{tabular}{|c|c|c|c|c|c|}
\hline \multirow[b]{3}{*}{ Diagnosis } & \multicolumn{4}{|c|}{ OPERATION } & \multirow[b]{3}{*}{ Grade 5: Deteriora } \\
\hline & \multicolumn{2}{|c|}{ Free from Medical Care } & \multirow[b]{2}{*}{$\begin{array}{l}\text { Grade 3: Improved, } \\
\text { Some Symptoms } \\
\text { Requiring Treatment }\end{array}$} & \multirow[b]{2}{*}{ Grade 4: Unchanged } & \\
\hline & $\begin{array}{l}\text { Grade 1: No } \\
\text { Symptoms }\end{array}$ & $\begin{array}{l}\text { Grade 2: Slight } \\
\text { Symptoms and No } \\
\text { Treatment Required }\end{array}$ & & & \\
\hline Hypochondriasis & 1 & 1 & 1 & - & 一 \\
\hline Chronic pain & - & - & 1 & 3 & 一 \\
\hline Hysteria & - & 1 & 2 & 1 & - \\
\hline Obsessional compulsive states & 2 & 2 & 1 & 2 & - \\
\hline Anxiety states & 3 & 1 & 3 & 2 & - \\
\hline Depressions & 17 & 3 & 3 & - & - \\
\hline Total & 23 & 8 & 11 & 8 & - \\
\hline
\end{tabular}

TABLE III

AGE DISTRIBUTION OF THE PATIENTS STUDIED

\begin{tabular}{lcc}
$\begin{array}{l}\text { Age Group } \\
(y r .)\end{array}$ & $\begin{array}{l}\text { Restricted Orbital } \\
\text { Undercutting }\end{array}$ & Stereotactic Tractotomy \\
\hline $20-29$ & 48 & 3 \\
$30-39$ & 111 & 9 \\
$40-49$ & 126 & 8 \\
$50-59$ & 92 & 6 \\
$60-69$ & 58 & 15 \\
$70-79$ & 15 & 7 \\
$80-89$ & 0 & 2 \\
& 450 & 50
\end{tabular}

has certain advantages in comparison with the 'open' undercutting operation. Of a total of 554 cases submitted to the orbital undercutting operation, there were an overall mortality of $7(1.3 \%)$. Two deaths were in hypertensives: one died in status epilepticus, another with hemiplegia soon after operation. This operation should not be performed on patients with gross hypertension. Ninety cases had been treated by stereotactic operations by March 1965 without mortality, operations having been performed with satisfactory improvement in hypertensive patients suffering from cardiac fibrillation, cardiac decompensation, or hemiplegia, and also in patients suffering from chronic pulmonary tuberculosis or bronchiectasis, and a patient who had previously sustained a hemiplegia and subarachnoid haemorrhage from an intracranial aneurysm.

EPILEPSY The reduction of intracerebral scarring achieved by stereotactic operation should reduce the risk of post-operative epilepsy, which complicates undercutting. Of a total of 475 patients treated by undercutting, 46 (approximately 10\%) developed seizures some time after operation: 23 exhibited single seizures, which in three cases were definitely attributable to the use of tranquillizers as described by Liddell and Retterstöl (1957). In 90 cases treated by stereotactic tractotomy three patients had a single seizure in the first 24 hours after operation but there has so far been no example of epilepsy as a delayed complication.

INCONTINENCE Incontinence is not a feature of the recovery stage following either stereotactic operation or undercutting, a finding which is in keeping with the observations of Andrew and Nathan (1964). In a series of 90 cases treated by stereotactic operation one elderly patient with marked cerebral atrophy exhibited incontinence for two months but it is probable that the effects of the atrophy played a contributory part in this complication. By contrast, a 
patient of 81 , suffering from depression and increasing hypochondriasis, presented a bizarre picture, making repeated booming noises and constantly protruding her tongue. There had been a visible deterioration in her physical condition and she had become continually incontinent before operation, but after she returned to the sending hospital she was reported within three weeks of operation to have greatly improved. Incontinence had ceased.

PERSONALITY CHANGE AND WORKING CAPACITY In Tredgold's review $5 \%$ of patients treated by undercutting exhibited some deterioration in behaviour resulting from damage at operation. Detailed comparison in cases of stereotactic operation must await a psychiatric review, but there has been no obvious change in the 90 cases so far treated. Except in so far as elderly patients are handicapped by physical defects, the improvement in working capacity appears to be equal to that obtained following undercutting.

\section{SUMMARY AND CONCLUSIONS}

Ninety patients have been treated by stereotactic tractotomy, by implanting radioactive Ytrrium in the substantia innominata under radiological control. Evidence is presented to show that the operation is particularly effective in the treatment of chronic depression.

Since good results can be obtained by stereotactic operation in patients of advanced years and poor physical condition, relief can be extended to geriatric patients.

The majority of patients suffering from depressive illness can be improved by surgical means when psychiatric treatment fails.

I should like to express my gratitude to all those who have helped in this investigation; to Sir Wilfred Le Gros Clark and Drs. Cowan and Powell of Oxford University for discussing the anatomical factors and their original work; to my psychiatric colleagues including Dr. Roger Tredgold, Dr. Strom-Olsen, Dr. Sargant, Dr. David Rice, Dr. Ainslie, Dr. Bram, and Dr. Backus, and many others who have referred most interesting cases, and my colleagues in the Physics Department and Department $Z_{\mathbb{Q}}$ of Radiology at the Postgraduate Medical School who have developed the technique described and who have $O$ given so much of their time to ensure the accuracy of operation; also to Miss K. Sykes for her accurate 6 observations during the survey of the undercutting series.

Figures 1, 3, 4, 5a, and 6 are reproduced by kind permission of the Editor and publishers of the British Journal of Surgery.

\section{REFERENCES}

Andrew, J., and Nathan, P. W. (1964). Lesions of the anterior frontal lobes and disturbances of micturition and defaecation. Brain 87, 233-262.

Beck, E. (1949). A cytoarchitectural investigation into the boundaries of cortical areas 13 and 14 in the human brain. J. Anat. (Lond.) 83, 147-157.

- McLardy, T., and Meyer, A. (1950). Anatomical comments on psychosurgical procedures. J. ment. Sci., 96, 157-167.

Cowan, W. M., and Powell, T. P. S. (1956). A note on terminal degeneration in the hypothalamus. Ibid., 90, 188-192.

Knight G. C. (1943). Observations on surgical technique. Ibid., 89, 174-181.

- (1960). 330 cases of restricted orbital cortex undercutting. Proc. roy. Soc. Med., 53, 728-732.

- (1964). The orbital cortex as an objective in the surgical treatment of mental illness. 450 cases of open operation and the $\infty$ results of development of the stereotactic approach. Brito J. Surg., 51, 114-124.

-, and Tredgold, R. F. (1955). Orbital leucotomy-a review of 5 \% cases. Lancet, 1, 981-985.

Le Gros Clark, W. E., and Meyer, M. (1950). Anatomical relatior ships between the cerebral cortex and the hypothalamus Brit. med. Bull., 6, 341-345.

Liddell, D. W., and Retterstöl, N. (1957). The occurrence of epileptî fits in leucotomized patients receiving chlorpromazine therap J. Neurol. Neurosurg. Psychiat., 20, 105-107.

McCaul, I. R. (1959). A method for the localization and productiơ of discrete destructive lesions in brain. Ibid., 22, 109-11 25

Meyer, A., and Beck, E. (1945). Neuropathological problems arising from prefrontal leucotomy. J. ment. Sci., 91, 411-425.

- and McLardy, T. (1948). Posterior cuts in prefrontal leucotomy : A clinico pathological study. Ibid., 94, 555-564.

Nauta, W. J. H. (1961). Fibre degeneration following lesions of the amygdaloid complex in the monkey. J. Anat. (Lond.), 95, 515-531.

Powell, T. P. S., Cowan, W. M., and Raisman, G. (1963). Olfactory relationships of the diencephalon. Nature (Lond.), 199, 710-712.

Pippard, J. (1962). Leucotomy in Britain today. J. ment. Sci., 108, 249-255.

Sykes, M. K., and Tredgold, R. F. (1964). Restricted orbital undercutting: a study of its effects on 350 patients over the ten years 1951-1960. Brit. J. Psychiat., 110, 609-640.

Wall, P. D., Glees, P., and Fulton, J. F. (1951), Corticofugal connexions of posterior orbital surface in rhesus monkey. Brain, 74, 66-71.

Ziegler, L. H., and Osgood, C. W. (1945). Edema and tropic disturbances of the lower extremities complicating prefrontal lobotomy. Arch. Neurol. Psychiat., (Chic.) 53, 262-268. 